\title{
Total Polyphenol Content of Green, Roasted and Cooked Harar and Yirgacheffee Coffee, Ethiopia
}

\author{
ASFAW, G; "TEFERA, M \\ Department of Chemistry, University of Gondar, P. O. Box 196, Gondar, Ethiopia \\ *Corresponding Author Email: mollatef2001@gmail.com; Tel: (+251)913141619
}

\begin{abstract}
The effect of solvent composition on the total polyphenols content of green, roasted coffee and traditional coffee beverage preparation stages (Abol, Tona and Bereka) were studied by UV-Vis spectroscopy. The maximum extracted polyphenol of $640.3 \mathrm{mg} \mathrm{GAE} / 100 \mathrm{~g}$ and $641.9 \mathrm{mg}$ GAE/100 g were obtained at Harar and Yirgacheffee green coffee extracts with at $85 \%$ methanol, respectively. The results showed that total phenolic contents of extracts were found to be in the order of green $>$ roasted $>$ cooked (Abol $>$ Tona $>$ Bereka) in both coffee samples. Application of ANOVA revealed that a significant variation $(\mathrm{p}<0.05)$ was noted between the green, roasted, Abol, Tona and Breka coffee processing procedures. In general, this study revealed that there was a loss of substantial amount of total polyphenols through the traditional way of coffee brewing, probably ascribed to continuous provision of heating leads to degradation of existing polyphenols and formation of less stable and volatile products.
\end{abstract}

\section{DOI: https://dx.doi.org/10.4314/jasem.v24i1.27}

Copyright: Copyright $\left({ }^{\circ} 2020\right.$ Asfaw and Tefera. This is an open access article distributed under the Creative Commons Attribution License (CCL), which permits unrestricted use, distribution, and reproduction in any medium, provided the original work is properly cited.

Dates: Received: 30 November 2019; Revised: 20 December 2019; Accepted: 23 December 2019

Keywords: Coffee, Green, Roasted, Cooked, Polyphenol

Coffee is the most commercialized food product, which is widely consumed beverage in the world (Miroslav et al. 2018). Coffee trees are grown around Asia, Africa, South America and Caribbean region. Among commonly available coffee species, only two coffee species: Arabica (coffea Arabica), which accounts $75 \%$ and Robusta (coffea Canephora), which accounts $25 \%$ are highly used for commercial purpose (Ivana et al., 2011). Historically, coffee Arabica was originated from the highlands of Ethiopia and accounts approximately about $66-70 \%$ of commercial production in world coffee (Tewabe and Libsu, 2015). In Ethiopia, coffee is one of the most consumed hot drink in every household after prepared through various hot brewing (cooking) methods, whereby the hot water solubilizes and numerous organic compounds extracted from the roasted coffee ground (Giovanni et al., 2015). Green coffee, which refers to unroasted or raw bean is a good source of compounds such as chlorogenic acids, hydroxycinnamic acids, caffeine and caffeic acid which possessing antioxidant and radical scavenging activities. However, during roasting process chlorogenic acids are particularly degraded and the content of phenolic compounds as well as antioxidant capacity in coffee decreases. As a result, green coffee beans seem to be a better source of these beneficial compounds (Valentin and Watling, 2011). Although the main reasons of preferring coffee consumption are due to flavor and stimulating effect of caffeine for several years, the green coffee has recently received considerable attention due to the tendency of showing antihypertensive effects, preventive effects on diabetes and to reduce visceral fat and body weight (Sevcan et al., 2017; Valentin and Watling, 2011). In addition to the well-known stimulant properties of caffeine, studies have also indicated that its antioxidant potential through the in vitro inhibition of lipid peroxidation induced by free radicals (Castro et al., 2018). However, excessive intake of caffeine can lead to irritability, mutation effects suchas inhibition of DNA, anxiety and tremors, among other side effects (Tefera et al., 2016). The coffee beans first roasted at a temperature of 200-300 ${ }^{\circ} \mathrm{C}$, which helps to the formation of pleasant aroma and flavor through complex chemical changes. Besides to this, roasting may lead to oxidation and thermal degradation of phenolic compounds and the formation of new melanoidins, as well as the formation of other Maillard reaction products (Giovanni et al., 2015; Tamilmani and Pandey, 2015). Then, the roasted coffee ground in to powder in order to increase the solubility in hot water during brewing. Finally, the ground coffee and boiling water are combined in a boiling pot or kettle and left to brew for a few minutes for a temperature of between 90 and $95{ }^{\circ} \mathrm{C}$, which allow most of the active substances pass into the beverage from the coffee powder (Giovanni et al., 2015). In Ethiopia, coffee is consumed almost in all 
households in a daily basis which is prepared through various hot brewing methods, whereby the hot water solubilizes and numerous organic compounds were extracted from the roasted coffee grounds (Giovanni et al., 2015). Harar and Yirgacheffee coffees are the most commercially important varieties grown in the eastern and southern region of the country, respectively. Not only the origin or variety, but also blending and grinding of coffee beans, brewing process influence the antioxidant composition of the coffee. A wide range of coffee preparation techniques significantly affects the taste and aroma of coffee infusions. In the process of brewing procedures the components of coffee are extracted through decoction, infusion and pressure (Celik and Gokmen, 2018).

The consumption of foods containing polyphenols such fruits, vegetables, leguminous plants and cereals; and beverages such as tea and coffee accompany with prevention and reduction of the risk of diseases associated to free radical reactions. These are due to capability of phenols to donate electrons as well as the effectiveness of stabilizing radical intermediates in the prevention of oxidation at cellular and physiological level. The amount of phenolic compounds in plants is determined by the type of solvent (polarity) used for extraction, the degree of polymerization of phenols and their interaction (Faten et al., 2014). The aim of this study was to investigate the total polyphenol content in green coffee and evaluate the effect of roasting and traditional Ethiopian coffee brewing procedure on the total polyphenol content in two coffee varieties (Harar and Yirgacheffee coffees).

\section{EXPERIMENTAL}

Chemicals and Instruments: Folin-Ciocalteu (FC) reagent, gallic acid, sodium carbonate $\left(\mathrm{Na}_{2} \mathrm{CO}_{3}\right)$, methanol and distilled water were used in this study. All chemicals were of highest analytical grade. Deionised water was used for the preparation of solutions.

The total polyphenol content was determined with UV-VIS Spectrophotometer (Microprocessor UV-VIS Double Beam Spectrophotometer), quartz cuvette, ACB plus-600H Digital balance, aluminum foil, centrifuge, Whatman No.1 filter paper and aluminum foil.

Coffee Sample Preparation and Extraction: The two Ethiopia's premium coffee samples (Harar and Yirgacheffee) were provided by Ethiopia Commodity Exchange (ECX) Gondar branch office. Prior to analysis, the green coffee was sterilized at $120^{\circ} \mathrm{C}$ for 5 min in oven to remove the moisture (Oliveir et al., 2013). Consequently, the sterilized beans was grounded and reserved at $-4^{\circ} \mathrm{C}$ until the analysis carried out

During roasting, the green beans are heated at 200$240^{\circ} \mathrm{C}$ for $10-15 \mathrm{~min}$ depending on the degree of roasting required, which is generally evaluated by color (Andriot et al., 2004). The coffee samples (75 g) roasted with charcoal as a source of energy using traditional methods of preparing coffee at a household level and cooled for $10 \mathrm{~min}$ in order to prevent excessive roasting. Prior to analysis, roasted samples were grounded usually by electric grinder to a fine powder. Of these amount, $17 \mathrm{~g}$ of each type of coffee powder was employed directly for TPC analysis, while the remaining $58 \mathrm{~g}$ powdered coffee was dissolved in water in in round-bottomed, black clay coffeepot (known as a jebena) for brewing in three rounds as Abol (first brewed and strongest one), Tona (second brewed and less strong) and Bereka (third brewed and the weakest). However, in each level of brewery 50 $\mathrm{mL}$ of coffee beverage was taken through Erlenmeyer flask for total polyphenol determination. Finally, the roasted and brewed coffee stored in the refrigerator till TPC analysis was carried out.

Extraction of bioactive compound which are found in various parts of the plant is the first step for the analysis of chemicals such as polyphenols, flavonoids and antioxidants. This extraction may take place from fresh, frozen or dried plant samples through grinding, milling and homogenization treatment which may be preceded by freeze drying or air drying. However, the former drying method provides higher level of phenolics content than the later (Boeing et al., 2014).

The nature of solvent is one of the factors which affect the efficiency of polyphenols extraction from different sample matrices. Solvents such as methanol are frequently used for the extraction of bioactive compounds (Złotek et al., 2014). In order to find better extraction of total phenolic compounds in each stage of coffee samples, the effect of solvent ratio (methanol: water) was studied simultaneously. In this study, $1.0 \mathrm{~g}$ of green and roasted coffee powder mixed with various methanol solutions $(100 \%, 95 \%, 90 \%$, $85 \%, 80 \%, 75 \%$ and $70 \%$ ) in $100 \mathrm{~mL}$ Erlenmeyer flask. Subsequently, each sample was stirred with magnetic stirrer for $20 \mathrm{~min}$ and kept at room temperature for $24 \mathrm{~h}$. Finally, the solution was filtered using Whatman No. 1 filter paper and the supernatant stored at $-4{ }^{\circ} \mathrm{C}$ until analysis.

Total phenolic Content (TPC) Determination: The TPC of coffee extract was determined based on spectrophotometric method using Folin-Ciocalteu's reagent (Singleton et al., 1999) with some 
modifications. Briefly; $0.5 \mathrm{~mL}$ of methanolic solution extract was added to $2.5 \mathrm{~mL}$ of dilute Folin-Ciocalteu reagent in a test tube. After a while, $2 \mathrm{~mL}$ of $7.5 \%$ sodium carbonate solution was added to create basic media for the reaction. Then, the solution was covered by aluminum foil and left for $1 \mathrm{~h}$ at room temperature to complete the reaction. The absorbance was recorded at $760 \mathrm{~nm}$ using UV-Vis spectrophotometer against the blank solution. The measurement was compared to a calibration curve prepared with gallic acid (GA) solution, and the total phenolic content was expressed as milligrams of gallic acid equivalents per gram dry coffee beans (mg GAE/g).

Statistical Analysis: All measurements were performed in triplicates and results reported as mean \pm standard deviation. The results the data were analysed statistically using the IBM SPSS software (version 20) and the mean values of TPC were compared by Tukey's HSD (homogeneous subset difference) test to assess the existence of significant differences betweenthe means due to coffee origin, extraction solvent composition, as well as to establish the differences in the phenolic content among the various coffee processing procedures.

\section{RESULTS AND DISCUSSION}

Instrumental Calibration: The standard solutions of gallic acid were prepared freshly by diluting the intermediated standard solutions $(1000 \mathrm{mg} / \mathrm{L})$. The instrument was calibrated using seven series of working standards $(50,100,200,300,400$ and 500 $\mathrm{mg} / \mathrm{L})$. The calibration curve was linear in the studied range with a correlation coefficient of 0.9985 , which impliesa strong linear relationship between absorbance and concentration.

Analysis of total phenolic content (TPC): In this study, a blue-colored solution was produced when the active extracts or fractions from coffee beans reacted with Folin-Ciocalteau reagent in an alkaline medium, which is due to the presence of phosphomolybdicphosphotungstic-phenol complex (Kumar et al., 2018). Various compositions $(70 \%, 75 \%, 80 \%, 85 \%$,
$90 \%, 95 \%$ and $100 \%$ ) of methanol solutions were tested as solvent mixture for extraction of total polyphenol. The ratio which provided the optimal absorbance of all coffee samples was 8.5:1.5 methanol to water ratio. It was found that the TPC of green, roasted and brewed (Bereka, Tona and Abol) coffee samples extract increased with increasing methanol content from $70 \%$ to $85 \%$ and then decreased with increasing methanol content. The loss of TPC can be attributed to the leaching of water soluble compounds into the cooking water as well as the breakdown of these compounds during roasting and cooking (Preti et al., 2017). It may also be caused by the possible complex formation of some phenolic compounds in the extract that are soluble in methanol (Votavova et al., 2009). Table 1 provides an overview of the total polyphenol content of green, roasted and brewed Harar coffee. According to the data displayed in Table 1 and Figure 1, Harar green coffee showed the highest total phenolic content compared to the roasted and brewed. Total phenolic content in green coffee varied from $580.9 \mathrm{mg} \mathrm{GAE} / 100 \mathrm{~g}$ in 70\% methanol extract to $640.3 \mathrm{mg}$ GAE $/ 100 \mathrm{~g}$ in $85 \%$ methanol extract. In roasted coffee, the highest TPC was $611.6 \mathrm{mg}$ $\mathrm{GAE} / 100 \mathrm{~g}$ at $85^{\circ} \mathrm{C}$ and the least $547.3 \mathrm{mg} \mathrm{GAE} / 100$ $\mathrm{g}$ at $100^{\circ} \mathrm{C}$. At all solvent composition the levels of TPC were lower than green coffee higher than roasted coffee. This is due to the fact that on roasting, phenolic compounds are partially degraded and/or bound to polymer structures depending on roasting conditions. Besides, it is known that during the roasting process, the amount of polyphenols undergoing polymerization or autoxidation reactions increases, which probably leads to the formation of less active antioxidant substances (Cammerer et al., 2006). Data also showed that among the coffee brewedprocessesat all extraction volume of methanol, the highest TPC was found in Abol, which ranged from 525.5 to $556.3 \mathrm{mg}$ GAE/ 100 $\mathrm{g}$ and the least in Bereka, ranged from 184.6 to 241.9 mg GAE/100 g of dry sample. These cooking processes caused a number of changes in physical characteristics and chemical composition such as degradation of polyphenol. The results also indicated that polyphenolic compounds were very sensitive to heat treatment (Preti et al., 2017).

\begin{tabular}{|c|c|c|c|c|c|}
\hline \multirow[t]{2}{*}{$\%$ methanol } & \multirow[t]{2}{*}{ Green } & \multirow[t]{2}{*}{ Roasted } & \multicolumn{3}{|c|}{ Brewed } \\
\hline & & & Abol & Tona & Bereka \\
\hline 70 & $580.9 \pm 0.50^{\mathrm{a}}$ & $575.7 \pm 4.72^{\mathrm{b}}$ & $541.9 \pm 0.3^{\mathrm{c}}$ & $363.0 \pm 0.20^{\mathrm{d}}$ & $184.7 \pm 0.21^{\mathrm{e}}$ \\
\hline 75 & $591.3 \pm 0.43^{\mathrm{a}}$ & $578.9 \pm 0.12^{\mathrm{b}}$ & $543.6 \pm 0.21^{\mathrm{c}}$ & $376.3 \pm 0.14^{\mathrm{d}}$ & $199.2 \pm 0.35^{\mathrm{e}}$ \\
\hline 80 & $637.4 \pm 0.14^{\mathrm{a}}$ & $587.9 \pm 3.20^{\mathrm{b}}$ & $550.8 \pm 0.28^{c}$ & $397.1 \pm 0.21^{\mathrm{d}}$ & $184.6 \pm 0.07^{\mathrm{e}}$ \\
\hline 85 & $640.3 \pm 3.50^{\mathrm{a}}$ & $611.6 \pm 5.20^{\mathrm{b}}$ & $556.3 \pm 0.21^{\mathrm{c}}$ & $403.8 \pm 0.15^{\mathrm{d}}$ & $241.9 \pm 5.14^{\mathrm{e}}$ \\
\hline 90 & $611.3 \pm 0.21^{\mathrm{a}}$ & $575.5 \pm 0.71^{\mathrm{b}}$ & $529.3 \pm 0.70^{\mathrm{c}}$ & $400.4 \pm 1.14^{\mathrm{d}}$ & $212.4 \pm 3.11^{\mathrm{e}}$ \\
\hline 95 & $612.6 \pm 2.21^{\mathrm{a}}$ & $574.3 \pm 0.28^{\mathrm{b}}$ & $525.5 \pm 0.49^{c}$ & $397.9 \pm 0.10^{\mathrm{d}}$ & $206.6 \pm 6.21^{\mathrm{e}}$ \\
\hline 100 & $614.3 \pm 3.01^{\mathrm{a}}$ & $547.3 \pm 0.34^{\mathrm{b}}$ & $504.9 \pm 0.49^{c}$ & $387.0 \pm 0.11^{\mathrm{d}}$ & $205.8 \pm 2.14^{\mathrm{e}}$ \\
\hline
\end{tabular}






Fig 1. Total polyphenols content of Harar coffee at various methanol compositions

As shown in Table 2 and Figure 2, a similar trend was also observed in Yirgacheffee coffee. Green coffee contained the highest phenolic content in the range of 593.7 to $641.9 \mathrm{mg}$ GAE/ $100 \mathrm{~g}$ in $70 \%$ and $85 \%$ methanol extracts, respectively. Regarding tobrewed coffee, the highest and the least were found in Abol (584.3mg GAE/100 g) and Bereka brewed coffee (235.7 $\mathrm{mg} \mathrm{GAE} / 100 \mathrm{~g}$ ) at $85 \%$ methanol solution, respectively. In this coffee variety, the TPC decreases in the order of: Green $>$ roasted $>$ Abol $>$ Tona $>$ Bereka, indicating that during roasting and in the process of brewing the content of phenolic compounds in coffee decreased. There is also agreement in the literature about the influence of roasting on coffee. A study by Jeszka-Skowron et al. confirmed that during roasting and brewing process of coffee part of the compounds transformed in to other forms and even some of them are highly degraded and reduced to less than $1 \%$ of the original content (Jeszka-Skowron et al., 2015). Similar observations were also detected by Sanchez-Gonzalez et al., 2005. It was found that the contents of total polyphenols in coffee bean extracts were higher than brewed coffee (Sanchez-Gonzalez et al., 2005). Tamilmani and Pandey also pointed out that roasting leads to degradation of existing polyphenols (Tamilmani and Pandey, 2015). The concentrations of total polyphenols at the optimal condition (85\% methanol) for Harar coffee were found to be relatively higher than that obtained in Yirgacheffee coffee in all the green, roasted and brewed samples, this perhaps due to the varied environmental growing conditions that could affect phenolic compound composition.

Table 2. Total polyphenol content of Yirgacheffee coffee at various methanol compositions (mg of GAE/100 g)

\begin{tabular}{llllll}
\hline$\%$ methanol & Green & Roasted & Abol & Tona & Bereka \\
\hline 70 & $593.7 \pm 0.17^{\mathrm{a}}$ & $589.7 \pm 0.51^{\mathrm{b}}$ & $574.6 \pm 0.33^{\mathrm{c}}$ & $326.0 \pm 0.49^{\mathrm{d}}$ & $192.5 \pm 0.071^{\mathrm{e}}$ \\
75 & $600.6 \pm 0.32^{\mathrm{a}}$ & $596.9 \pm 0.35^{\mathrm{b}}$ & $576.4 \pm 0.50^{\mathrm{c}}$ & $331.1 \pm 0.21^{\mathrm{d}}$ & $203.7 \pm 0.35^{\mathrm{e}}$ \\
80 & $624.7 \pm 0.22^{\mathrm{a}}$ & $597.5 \pm 0.51^{\mathrm{b}}$ & $580.6 \pm 0.34^{\mathrm{c}}$ & $346.3 \pm 0.28^{\mathrm{d}}$ & $207.8 \pm 0.14^{\mathrm{e}}$ \\
85 & $641.9 \pm 0.35^{\mathrm{a}}$ & $632.4 \pm 0.50^{\mathrm{b}}$ & $584.3 \pm 0.23^{\mathrm{c}}$ & $370.9 \pm 0.35^{\mathrm{d}}$ & $235.7 \pm 0.21^{\mathrm{e}}$ \\
90 & $612.9 \pm 0.35^{\mathrm{a}}$ & $571.9 \pm 0.35^{\mathrm{b}}$ & $558.5 \pm 0.51^{\mathrm{c}}$ & $369.2 \pm 0.14^{\mathrm{d}}$ & $230.3 \pm 0.14^{\mathrm{e}}$ \\
95 & $611.4 \pm 0.50^{\mathrm{a}}$ & $557.3 \pm 0.35^{\mathrm{b}}$ & $550.6 \pm 0.30^{\mathrm{c}}$ & $358.8 \pm 0.28^{\mathrm{d}}$ & $229.7 \pm 0.07^{\mathrm{e}}$ \\
100 & $604.9 \pm 0.35^{\mathrm{a}}$ & $550.3 \pm 0.35^{\mathrm{b}}$ & $546.0 \pm 0.23^{\mathrm{c}}$ & $353.3 \pm 0.14^{\mathrm{d}}$ & $205.5 \pm 0.20^{\mathrm{e}}$ \\
\hline \multicolumn{5}{c}{ Values with different letters in the different column are significant different at $p<0.05$}
\end{tabular}

Values with different letters in the different column are significant different at $p<0.05$

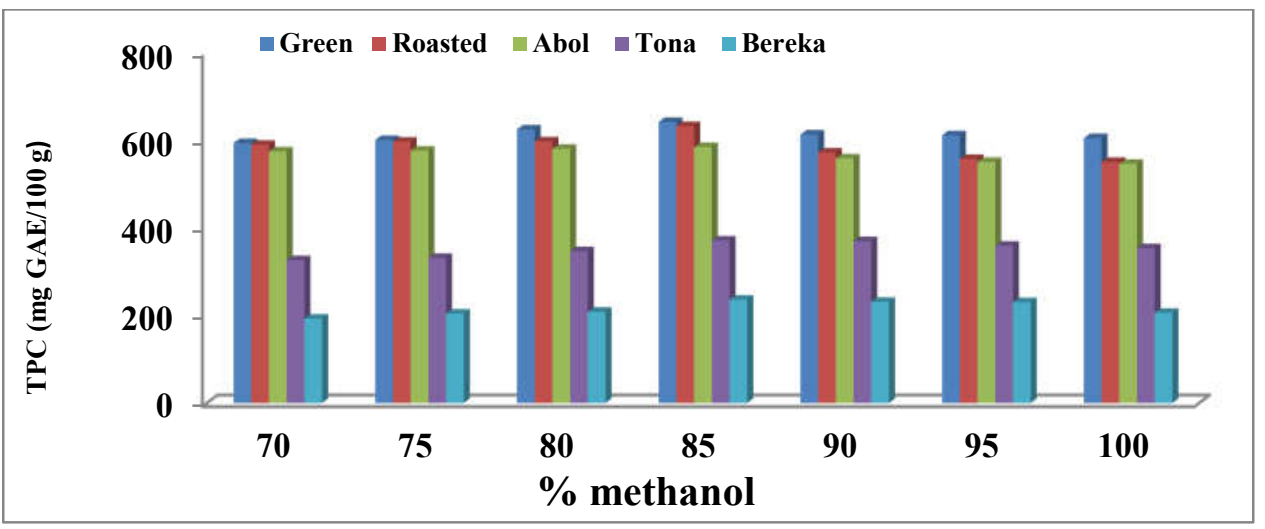

Fig 2. Total polyphenols content of Yirgacheffee coffee at various methanol compositions 
As can be seen in Tables 1 and 2, no significant differences $(p>0.05)$ were observed between types of coffee varieties (Harar and Yirgacheffee) and various composition of extraction solvent (percentage of methanol). However, there were significant differences $(p<0.05)$ between green, roasted, Abol, Tona and Bereka.

Conclusion: The aim of this study was to assess the effects of roasting and different stages of cooking (brewing) of coffee in the value of total polphenol. The results showed that the green coffee contained the highest polyphenols content than roasted and cooked coffee. Similarly, Bereka (third brewed) possessed the least total polyphenol content compared with Abol (first brewed) and Tona (second brewed). This change might be due to continuous provision of heat that degrades the polyphenols and the volatile polyphenols may evaporate.

\section{REFERENCES}

Andriot, I.; Lequere, J.; Guichard; E. (2004). Interactions between coffee melanoidins and flavor compounds: impact of freeze-drying (method and time) and roasting degree of coffee on melanoidins retention capacity. Food chem. 85: 289-294.

Boeing, J.; Barizao, E.; Silva, B.; Montanher, P.; Almeida, V.; Visentaine, J. (2014). Evaluation of solvent effect on the extraction of phenolic compounds and antioxidant capacities from the berries: application of principal component analysis. Chem. Central J. 8: 1-9.

Cammerer, B.; Kroh, L. (2006). Antioxidant activity of coffee brews. Euro. Food Res. Technol. 223: $469-474$

Castro, A.; Oda, F.; Almeida-Cincotto, M.; Davanço, M.; Chiari-Andreo, B.; Cicarelli, R.; Peccinini, R.; Zocolo, G.; Ribeiro, P.; Corrêa, M.; Isaac, V.; Santos, A. (2018). Green coffee seed residue: A sustainable source of antioxidant compounds. Food Chem. 246: 48-57

Celik, E.; Gokmen, V. (2018). A study on interactions between the insoluble fractions of different coffee infusions and major cocoa free antioxidants and different coffee infusions and dark chocolate. Food Chem. 255: 8-14.

Faten, M.; Hanen, F.; Riadh, K.; Chedly, A. (2014). Total phenolic, flavonoid and tannin contents and antioxidant and antimicrobial activities of organic extracts of shoots of the plant
Limoniumdelicatulum. J. Taibah Uni. Sci. 8: 216224

Giovanni, C.; Manuela, C.; Gianni, S.; Sauro, V. (2015). The influence of different types of preparation (espresso and brew) on coffee aroma and main bioactive constituents. Int. J. Food Sci. Nutr. 66: 505-513

Gonzalez, S., Escrig, J., Calixto, S. (2005). In vitro antioxidant activity of coffees brewed using different procedures (Italian, espresso and filter). Food Chem. 90: 133-139

Ivana, H.; Ana, B.; Dunja, H.; Drazenka, K. (2011). Comparative study of polyphenols and caffeine in different coffee varieties affected by the degree of roasting. Food Chem. 129: 991-1000

Jeszka-Skowron, M., Zgoła-Grzeskowiak, A., Grzeskowiak, T. (2015). 'Analytical methods applied for the characterization and the determination of bioactive compounds in coffee'. Euro. Food Res. Technol. 240: 19-31.

Kumar, P., Reddy, R., Prakash, G.; Kumar, P. (2015). In vitro estimation of total phenolics and DPPH radical scavenging activity of Withania Somnifera extract. Pharma Innov. J. 7: 588-590

Miroslav, S.; Luca, R.; Peter, M.; Adam, S.; Luciano, N. (2018). Rapid sucrose monitoring in green coffee samples using multienzymatic biosensor. Food Chem. 254: 8-12.

Oliveira, G.; Mariad, D; Pereira, R.; Paiva, L.; Pradod, G.; Batista, L. (2013). Effect of different roasting levels and particle sizes on ochratoxinA concentration in coffee beans. Food Cont. 34: 651-656

Preti, R.; Rapa, M.; Vinci, G. (2017). Effect of steaming and boiling on the Antioxidant Properties and Biogenic Amines Content in Green Bean (Phaseolus vulgaris) Varieties of Different Colours. J. Food Qual. 1: 1-8.

Sandra, G.; Paula, C. (2011). Antioxidant potential of Artemisia argenteaL'Hér alcoholic extract and its relation with the phenolic composition. Res. Int. 44: 1620-1631

Sevcan, S.; Selda, M.; Murat, Y.; Münevver, A. (2017). Elemental composition of green coffee and its contribution to dietary intake. Food Chem. 215: $92-100$. 
Singleton, V.; Orthofer, R.; Lamuela-Raventos, R. (1999). Analysis of total phenols and other oxidation substrates and antioxidants by means of Folin-Ciocalteu reagent. Meth. Enzymo. 299: 152-178.

Tamilmani, P., Pandey, M. (2015). 'Optimization and Evaluation of phenolic compounds and their antioxidant activity from coffee beans'. Int. J. 3: 296-306.

Tefera, M.; Geto, A.; Tessema, M.; Admassie, S. (2016). Simultaneous determination of caffeine and paracetamol by square wave voltammetry at poly (4-amino-3-hydroxynaphthalene sulfonic acid)-modified glassy carbon electrode. Food Chem. 210: 156-162
Tewabe, B.; Libsu, S. (2015). Determination of Caffeine Content and Antioxidant Activity of Coffee, American J. Appl. Chem. 3: 69-76

Valentin, J.; Watling, R. (2013). Provenance establishment of coffee usingsolution ICP-MS and ICP-AES. Food Chem. 141: 98-104

Votavova, L.; Voldrich, M.; Sevcik, R.; Cizkova, H.; Mlejnecka, J.; Stolar, M.; Fleisman, T. 2009. Changes of Antioxidant Capacity of Robusta Coffee during Roasting, Czech. J. Food Sci. 27: 49-52

Złotek, U.; Mikulska, S; Nagajek, M.; Swieca, M. 2016. The effect of different solvents and number of extraction steps on the polyphenol content and antioxidant capacity of basil leaves (Ocimumbasilicum L.) extracts. Saudi J. Biol. Sci. 23: 628-633 